\title{
O empréstimo e suas influências linguístico-culturais: o caso do japonês
}

\author{
Loanwords and their Linguistic and \\ Cultural Influences: the case of J apanese
}

\author{
J éssica Câmara Siqueira*
}

Resumo: O objetivo do artigo é analisar os principais tipos de empréstimos observados na língua japonesa contemporânea, com intuito de identificar padrões de ocorrência e indícios de suas escolhas linguísticas. Tendo como base a revisão da literatura sobre o assunto, esses padrões de ocorrência são observados à luz da comparação com os empréstimos do português, demarcando-se suas similitudes e distinções. Concluímos que os empréstimos podem ter um importante papel na observação do nível de trocas e influências linguístico-culturais entre os povos.

Palavras-chave: Cultura; empréstimo; japonês; português.

Abstract: The aim of this paper is to analyze the main kinds of loanwords observed in contemporary J apanese language in order to identify their patterns of occurrence and the reasons for linguistic choices. Based on the literature review, these patterns of occurrence are compared to loanwords from Portuguese regarding their similarities and differences. As a conclusion, we can observe that loanwords have an important role in linguistic-cultural exchange and influence between cultures.

Keywords: Culture; J apanese; loanwords; Portuguese.

\footnotetext{
* Doutoranda em Letras no Programa de Filologia e Linguística Portuguesa da Universidade de São Paulo. E-mail: jessica.siqueira@usp.br
} 
SIQUEIRA, J.C. - O empréstimo e suas influências linguístico-culturais: o caso do japonês

\section{Introdução}

As línguas têm o caráter intrínseco de incorporar e adaptar o léxico de diferentes domínios. Essa dinamicidade das línguas é fruto não apenas das inevitáveis mudanças socioculturais de uma comunidade linguística, mas do contato que se estabelece entre os falantes de diferentes culturas. Esse fenômeno de incorporação de mudanças, internas e externas, é denominado de empréstimo.

Tal perspectiva tem como base a visão de BLOOMFIELD (1933), que parte de uma motivação cultural para entender o empréstimo como a adoção de determinados traços linguísticos não pertencentes a um sistema vernáculo tradicional. Assim, segundo o autor:

[... ] todas as comunidades que compartilham uma mesma língua ou dialeto aprendem com seus vizinhos. Tanto os objetos naturais como os manufaturados, passam de uma comunidade para outra, assim como seus padrões de ação, tais como procedimentos técnicos, práticas de guerra, ritos religiosos ou moldes de conduta individual (BLOOMFIELD 1933: 445).

Seguindo tal visão, o autor classifica os empréstimos em três tipos: os íntimos, os dialetais e os culturais. No primeiro caso, temos os empréstimos ocorridos dentro da mesma língua em comunidades próximas. No segundo tipo, as trocas ocorrem como fruto da convivência de diferentes falares num mesmo território. E por fim, nos empréstimos culturais, temos o contato de línguas diferentes que se relacionam por razões sociais, políticas econômicas e culturais.

Baseado na visão de BLOOMFILED (1933) calcada no intercâmbio linguístico entre diferentes comunidades de culturas distintas, SANDMAnN (1992) apresenta uma classificação baseada no nível de incorporação do empréstimo a outro sistema linguístico. Assim, o autor define três momentos para a incorporação do item lexical: o empréstimo lexical, quando o termo 
SIQUEIRA, J .C. - 0 empréstimo e suas influências linguístico-culturais: o caso do japonês

entra na língua sem tradução ou alteração de morfemas, mas podendo sofrer algum tipo de adaptação fonológica e ou ortográfica; o empréstimo semântico (ou decalque) que ocorre a partir da tradução ou substituição de morfemas, partindo da incorporação de uma ideia (podendo ou não ter uma alteração na estrutura); e o empréstimo estrutural que segue o modelo estrutural do léxico vernacular da língua, ocorrendo quando o termo já está bem integrado ao idioma (SANDMANn 1992).

Outra perspectiva para compreensão dos empréstimos é dada por GUILBERT (1975). Ao invés de uma motivação cultural, como a proposta por Bloomfiled, Guilbert justifica a entrada de um empréstimo por questões de economia e comodidade, quando o termo emprestado possui um conteúdo semântico mais rico a oferecer, ou mesmo quando a língua em questão não dispõe de determinado termo em um domínio. Dessa forma, para o autor, a noção de empréstimo está vinculada a um lexema externo à língua, que se integra a outro sistema por possuir uma informação mais importante que a contida no elemento vernacular.

Com essa mudança na noção de empréstimo, o autor também possui uma forma particular de classificação, designando os empréstimos como conotativos e denotativos. Os primeiros referem-se aos produtos e conceitos oriundos de um país estrangeiro, geralmente de caráter dominante econômica e cientificamente. Já os conotativos, originam-se de um determinado evento ou corrente de mudanças que demarcam um contexto (GUILBERT 1975).

Seguindo essa linha de estudo, ALves (1995) aponta três fases para a incorporação de um empréstimo em uma língua. Em um primeiro momento 0 empréstimo apresenta-se sob a forma de estrangeirismo, ou seja, um elemento claramente identificável como externo à língua receptora, uma vez que, para ser compreensível em um contexto, deve ser acompanhado de traduções, definições de seu significado ou mesmo o decalque, versão literal, de seu sentido. 0 segundo momento é quando o uso do empréstimo torna-se mais frequente e ele acaba sendo implantado na língua receptora. Nesta fase ele pode sofrer algumas adaptações fonológicas, morfológicas e ortográficas 
SIQUEIRA, J.C. - O empréstimo e suas influências linguístico-culturais: o caso do japonês

para adequar-se à estrutura da língua receptora. E por fim a fase final, em que é amplamente difundido e incorporado ao acervo lexical do idioma, podendo ser observado em obras lexicográficas, por exemplo.

No âmbito deste artigo, analisaremos apenas a primeira e a segunda fase do empréstimo, ou seja, as etapas em que ele ainda está sendo implantado e incorporado em um novo sistema linguístico. Como o objeto de análise são os empréstimos provenientes de línguas distintas, de caráter externo, não nos deteremos em explicitar exemplos dos casos de empréstimos internos, ocorridos dentro do próprio idioma entre domínios distintos.

O objetivo do artigo é analisar os principais tipos de empréstimos observados na língua japonesa contemporânea com intuito de identificar padrões de ocorrência e indícios de suas escolhas linguísticas. Num segundo momento esses padrões de ocorrência serão observados à luz da comparação com os empréstimos do português, a fim de enxergarmos similitudes e distinções. Tendo como base a revisão da literatura sobre o assunto, e tomando como referência os exemplos encontrados no Dicionário Japonês Português (MICHAELIS 2012) procuramos identificar, a partir dos empréstimos, traços socioculturais das línguas em questão.

O recorte utilizado para análise levou em conta cerca de 200 termos encontrados no dicionário japonês, observando-se os seguintes aspectos dos verbetes: entrada; transcrição em hiragana, katakana ou kanji; marca lexicográfica que indica o termo originado em língua estrangeira e suas acepções. A escolha dos termos se deu com base na indicação da marca linguística de termo estrangeiro, selecionados em média entre 10 e 15 termos por letra do dicionário. Complementarmente foi utilizado o Aulete Digital, dicionário em língua portuguesa que possui marca lexicográfica para termos estrangeiros; e o recurso do Google tradutor como auxílio às questões fonéticas, uma vez que essa ferramenta permite a audição da palavra. Por fim, as similitudes e distinções observadas foram colocadas em planilhas para facilitar a visualização dos termos, suas nuanças gráficas, fonéticas e semânticas. 
SIQUEIRA, J .C. - 0 empréstimo e suas influências linguístico-culturais: o caso do japonês

\section{Noções básicas sobre a língua japonesa}

Há vários estudos linguísticos que investigam as origens da língua japonesa. Contudo é recorrente observar que muitos confundem meras semelhanças tipológicas com o parentesco linguístico. Segundo Nalto (1979) há três principais correntes de estudo sobre as línguas que teriam parentesco com o japonês: a corrente das línguas nativas das Ilhas Okiwawa, a Sudoeste do J apão; a corrente coreana e a das línguas altaicas.

A primeira corrente trata da origem do falar de um conjunto de ilhas a Sudoeste do Japão que poderiam ter sido influenciadas pelos povos da Austrália, e que como resultado de trocas mútuas entre esses povos distintos tenha gerado o falar dessa região, que mais tarde influenciaria o japonês atual. Na verdade, a variante falada nessa região hoje é considerada um dos diversos dialetos falados no J apão (NAITO 1979).

A segunda corrente, também baseada numa proximidade geográfica, remonta a mais de 6000 anos atrás, quando o japonês teria se separado do coreano e se tornado outra língua. No entanto, até o século VI a totalidade da cultura chinesa era transmitida aos japoneses via Coreia, o em num primeiro momento poderia ter gerado certa confusão com o que era empréstimo ou o que era parentesco entre essas línguas. Estudos comparativos realizados por Aston (1879 apud NAITo 1979) revelam que as semelhanças entre essas línguas estavam principalmente ligadas à sintaxe, a exemplo da ordem da estrutura (Sujeito, Objeto e Verbo) e à morfologia, devido ao caráter aglutinante dos termos.

A terceira corrente, a das línguas altaicas, refere-se à família de línguas provenientes da Ásia Central, com referência geográfica às montanhas de Altai, a exemplo do mongol e do turco. A principal evidência do parentesco seria o traço de irregularidade marcado nas conjugações e declinações, uma vez que a irregularidade é um caráter dificilmente transmitido entre línguas que não possuem parentesco. Dentre as principais irregularidades NalTo 
SIQUEIRA, J.C. - O empréstimo e suas influências linguístico-culturais: o caso do japonês

(1979) destaca: a não ocorrência de grupos consonânticos no início das palavras; a não ocorrência de " $r$ " inicial; a harmonia vocálica, sem a coocorrência da mesma vogal na palavra; a ausência de gênero e artigo (determinação); o emprego de sufixos, partículas e desinências na construção de frases; o uso de posposição ao invés de preposição; a frequência de orações sem Suj eito; e uso de auxiliares verbais (jodôshi), usados para marcar nuanças verbais como negação, progressão e sugestão (verbos não possuem flexão de número, pessoa, tempo e modo).

Dentre as três correntes a mais aceita é a última, ratificada principalmente pelo rol de similaridades expostos. Além disso, a extensão das línguas al taicas também toca os falares chineses e coreanos, ambos de origem mongol, o que indicaria o parentesco comum em uma protolíngua. Todavia, apesar dessas similaridades, o japonês hoje está bem afastado dessa protolíngua comum (FUKASAWA 1983).

Além disso, Naito (1979) ressalta que é difícil delimitar tipologicamente a estrutura de uma língua a um único sistema absoluto, uma vez que dentro do mesmo sistema são possíveis diferentes combinações entre os elementos. E se considerarmos os inevitáveis contatos e trocas mútuas com outras línguas, também é difícil afirmar peremptoriamente quem influencia qual língua (MALMBERG 1976).

Considerando as variáveis expostas anteriormente podemos afirmar que predominantemente a estrutura da língua japonesa é aglutinante, embora tenha traços flexionais em menor escala. Esse caráter aglutinante indica a base de sua estrutura linguística, sintagmática, formada essencialmente de lexema + gramema.

Além da estrutura sintagmática mencionada anteriormente, é importante lembrar que a língua japonesa é representada graficamente pela composição de dois silabários isomórficos, o hiragana e o katakana, com cerca de 50 letras e o kanji, conj unto de caracteres ideográficos de origem chinesa, com mais de 3000 ideogramas. O hiragana é o silabário cursivo de aspecto arredondado utilizado principalmente na transcrição literal de um kanji. Já o 
SIQUEIRA, J .C. - 0 empréstimo e suas influências linguístico-culturais: o caso do japonês

katakana é o silabário de aspecto geométrico usado para a transcrição dos termos estrangeiros ao idioma (Bossong 2003).

Como o sistema gráfico em japonês é diferente do alfabeto romano utilizado em grande parte do Ocidente, foi elaborado em 1867, pelo Reverendo J ames Curtis Hepburn, um sistema de transliteração dos sons do japonês para o alfabeto romano. Posteriormente designado com o nome do reverendo, o sistema Hepburn foi criado com base nos sons do inglês, o que contribuiu para sua disseminação pela amplitude de anglicismos no japonês, principalmente surgidos no pós-guerra. Mesmo com algumas oposições tradicionalistas, o sistema é até hoje o principal método de transcrição para o alfabeto romano usado no J apão (Bossong 2003).

\section{Estrangeirismos ${ }^{1}$ no japonês}

O termo gairaigo em japonês é utilizado para designar o conjunto de palavras estrangeiras incorporadas à língua japonesa. Há registros do português, holandês, francês e alemão até a segunda metade do século XX, depois disso a grande maioria do gairaigo é de origem inglesa (Bossong 2003).

Os empréstimos portugueses no J apão têm origem no século XVI, quando os portugueses se estabelecem no país praticando o comércio e tentando catequisar os japoneses. A presença portuguesa durou cerca de 90 anos, quando em 1637, com a proibição do cristianismo, os portugueses abandonaram o território do Japão. Como principal herança deixaram a língua, que diferente de outros empréstimos incorporou-se tão bem ao japonês que acabou até sendo representada por kanji, o que não ocorreu, por exemplo, com o inglês, que posteriormente teve uma influência muito mais marcante (TORII 2007).

\footnotetext{
${ }^{1}$ Os exemplos utilizados nessa seção são retirados do Dicionário Japonês Português Michaelis de 2012.
} 
SIQUEIRA, J.C. - O empréstimo e suas influências linguístico-culturais: o caso do japonês

Do português desse período temos palavras como: botan (botão), koppu (copo), panko (aglutinação de pão + farinha), etc. Contudo, mesmo que grande parte dos termos tenha se integrado à língua, sendo até representados por kanji, hoje existem apenas cerca de 500 palavras remanescentes. Tais palavras designam basicamente termos históricos, usados para representar termos religiosos, relativos à atividade missionária dos jesuítas, ou palavras de conotação cultural (YAZAKI 1971).

Depois do português, outras línguas deixaram seus vestígios linguísticos no J apão, a exemplo do holandês, alemão, francês, inglês, russo, espanhol e italiano, sendo que os três últimos com menor influência. Em estudo comparativo dessas línguas Bossong (2003) analisa que até a década de 20 do século XX havia certo equilíbrio entre suas capas etimológicas. Todavia, após a Segunda Guerra houve um aumento na introdução de anglicismos no japonês. Resultado da influência socioeconômica dos EUA no país Pós-guerra observou-se nesse período a adoção de anglicismos em seu sentido estrito. Em números, enquanto nos anos 20 havia cerca de 80 anglicismos, na década de 60 eram cerca de 2400 registrados (Bossong 2003). Além disso, mesmo termos que teoricamente já existiam representados por outro estrangeirismo, a exemplo de termos religiosos como kristhian (cristão do português) são readaptados, tendo agora como base o inglês, ficando, nesse caso, kurisu chan.

Apesar da ampla incorporação dos anglicismos no japonês, o que aparentemente indicaria maior abertura e aceitação do que é externo à cultura nipônica, temos na grafia um contraponto para tal questão. Com exceção dos estrangeirismos mais remotos de origem portuguesa já integrados ao idioma e representados por kanji, todos os demais têm sua estratificação evidenciada pela grafia com o katakana. 0 katakana permite que o leitor identifique se o termo em questão é proveniente da tradição japonesa ou se são termos estrangeiros.

Além de o registro gráfico explicitar a presença do empréstimo como 0 katakana, há também evidências fonológicas que demarcam a identidade dos 
SIQUEIRA, J .C. - 0 empréstimo e suas influências linguístico-culturais: o caso do japonês

termos estrangeiros. As adaptações fonológicas mais que meras escolhas aleatórias são delineadas por um padrão fonético e morfológico.

A transcrição fonética do japonês para o alfabeto latino é feito através do rōmaji. Na verdade, esse sistema de romanização pode ser observado em três principais variantes: o Kunrei-shiki, o Nihon-shiki e o sistema Hepburn com suas subvariações (Bossong, 2003). Para fins dessa análise, selecionamos alguns exemplos do sistema Hepburn.

Um primeiro padrão de adaptação observado é a vocalização no término das palavras, a exemplo de pasupoto (passport) e pinku (pink). Diferente do inglês, que tem um vasto vocabulário com palavras que terminam em consoantes, no japonês são raras essas terminações. Primeiro por ser formado de silabários, constituídos basicamente pela estrutura consoante + vogal. Depois pelo fato do japonês possuir essencialmente sílabas abertas, ou terminadas em nasal, o que força os grupos consonânticos serem reduzidos em relação às vogais finais.

É interessante observar que há maior recorrência de terminações vocálicas primeiramente em "u", como nos casos de shatsu (shirt) e fairu (file), e depois em "o", como em daiyamondo (diamond) e paredo (parade). E quando a palavra estrangeira já possui a vogal final, geralmente nos casos do " $\mathrm{i}$ ", prolonga-se o som dessa vogal como nos casos de memori (memory), takushi (taxi), kyandi (candy).

Outro padrão observado é a substituição de alguns sons consonantais por outros, geralmente nos casos em que são ausentes nos silabários alguns fonemas, como o "I" e o " $v$ ", substituídos por " $r$ " e "b. Como exemplos dessa alteração, temos bejitarian, ao invés de vegetarian; e terebijon, ao invés de television.

O fonema [đ্]] também entra nesse tipo de adaptação tendo seu som aproximado ao fonema "d", como em orenji (orange), jinzu (jeans) e jazu (jazz). Já o som do " $x$ " ganha fonemas distintos para cada tipo de consoante, a exemplo de fakkusu (fax) e sekkusu (sexual). 
SIQUEIRA, J .C. - 0 empréstimo e suas influências linguístico-culturais: o caso do japonês

Por fim, há casos de incorporação sem grandes alterações fonéticas, raros casos em que a terminação da palavra não é um "u" ou "o", além de algumas exceções de palavras terminadas em consoantes. Como exemplos, podemos citar: piano, banana, kamera, pen (caneta) e fan.

\section{Estrangeirismos japoneses e portugueses- contraposições culturais}

Uma primeira constatação ao observar o padrão de incorporação dos empréstimos no japonês é que há uma tentativa de se manter, em algum nível, a identidade da língua. Tal identidade se dá tanto no nível gráfico, com o uso do katakana, como fonológico, seguindo um padrão de adaptação vocálica ao idioma.

A sociedade japonesa, mesmo abrindo-se à globalização nas últimas décadas, ainda está muito arraigada às suas tradições culturais. Enquanto exibe uma faceta muito atrelada à tecnologia de ponta, por outro lado tem uma faceta que veste quimonos, celebra seus rituais sagrados em templos xintoístas, preserva seus dialetos regionais e por que não, demarca o que é genuinamente seu a partir da língua?

Mesmo com a relevante influência americana no pós-guerra, marcando sua presença na importação linguística, é salutar verificar que a invasão dessas palavras não foi meramente incorporada, mas aceita e adaptada às exigências fonológicas e gráficas do sistema japonês.

Por outro lado, se formos olhar para a língua portuguesa no Brasil, que também teve a influência de diversas línguas no decorrer da história, mas que na segunda metade do século XX, assim como o Japão, foi invadida pela influência americana temos outro cenário. Na Língua Portuguesa os empréstimos têm uma facilidade maior de adesão e incorporação. Primeiramente justificável pela nossa excessiva valorização, e até em certa 
SIQUEIRA, J .C. - 0 empréstimo e suas influências linguístico-culturais: o caso do japonês

medida cultuamento do que é externo principalmente proveniente de países economicamente mais ricos, como EUA e países da Europa. No J apão por outra lado, a incorporação do inglês é facilmente justificável observando-se seu contexto sócio-político após a Segunda Guerra Mundial. Os EUA tiveram um importante papel na reconstrução do J apão no Pós-guerra, não apenas auxiliando nas questões sócio-políticas e econômicas, mas também deixando sua marca na cultura e na língua japonesa.

Mesmo considerando a relevância do inglês para ambos os idiomas, observamos que ele atende perspectivas distintas. Na língua portuguesa, no Brasil, acolhemos o estrangeirismo primeiro em sua forma e conteúdo originais, que em seguida passa por um período de peregrinação no qual poderão, ou não, ser feitas mudanças gráficas, fonéticas ou até semânticas. No japonês, desde quando o estrangeirismo entra no idioma ele já passa por duas transformações radicais: uma alteração fonética, para adaptar-se aos fonemas da língua, e uma alteração gráfica ao ser transliterado para o katakana. Além disso, existem as inevitáveis alterações semânticas, que possuem até uma designação específica as wasei eigo, ou seja, são palavras em inglês incorporadas ao léxico japonês, que sofreram alterações em seu significado (MILLer 2013).

Um exemplo dessa alteração pode ser dado com a palavra konsentsu, proveniente de consent em inglês, que como verbo designa consentir, ceder, dar permissão, ou seus substantivos: consentimento, permissão, anuência. No entanto, o sentido do termo em japonês altera-se para bondade e cordialidade, assumindo assim outra conotação.

Retomando a teoria apresentada, no caso a perspectiva de BLOOMFIELD (1933), observamos que que prevalece no J apão os empréstimos culturais, fruto das relações sócio-políticas, principalmente com os EUA. Além disso, ao retomarmos a classificação de GUILBERT (1975) podemos delimitar mais ainda o tipo de empréstimo no Japão, classificando-o essencialmente como denotativo, uma vez que os termos estão relacionados a produtos ou materiais de caráter mais pragmático e não que envolvam um conceito ideológico. 
SIQUEIRA, J.C. - O empréstimo e suas influências linguístico-culturais: o caso do japonês

Por fim, se retomamos as classificações de SAndmann (1992), voltadas ao nível de incorporação, observamos importantes distinções entre as línguas. Primeiro notamos que o fenômeno dos empréstimos lexicais, ou seja, aqueles que entram na língua sem tradução ou alteração morfofonêmica, são muito raros no Japão, ao contrário no português no Brasil. Segundo que os empréstimos semânticos, mesmo sendo comuns nos dois países, acabam por se intensificarem no J apão, assumindo muitas vezes profundas alterações conceituais nos termos incorporados. E no caso dos empréstimos estruturais, que se acomodam à estrutura da língua em que se instalam, observamos que no J apão ocorre uma transformação mais profunda do termo estrangeiro, uma vez que sofre alterações transliterais, ao ser traduzido para o katakana, gráficas ao ser representado no romanji, fonológicas ao se adaptar à fonética da língua japonesa e por fim semânticas, alterando seu núcleo sêmico.

Considerando essa maior resistência nipônica em incorporar integralmente os termos estrangeiros, procurando sempre enquadrá-los em seus padrões linguísticos vigentes, temos a hipótese de que os novos termos (neologismos) também teriam pouco espaço na língua japonesa, uma vez que também deveriam se adequar aos paradigmas da língua.

\section{Considerações finais}

0 empréstimo no japonês é facilmente identificável pelo nível gráfico, através do katakana, e fonológico, pelo padrão de adaptações sonoras feitas às palavras estrangeiras. Essas marcas têm um papel importante ao desvelar traços de purismo na incorporação de estrangeirismos no japonês. Seja por questões socioculturais, históricas ou econômicas observa-se certa resistência à incorporação de novos termos na língua

Por outro lado, o português do Brasil, incorpora mais facilmente os estrangeirismos, bem como possui uma produtiva criação neológica. Além 
SIQUEIRA, J.C. - 0 empréstimo e suas influências linguístico-culturais: o caso do japonês

disso, ao contrário do japonês que modula o termo estrangeiro ao seu paradigma fonético, gráfico e frequentemente ao semântico, o português muitas vezes "aceita" o termo estrangeiro integralmente, sem fazer adaptações linguísticas.

Segundo BAKTHIN (1992) um signo é um objeto ideológico que carrega em si a visão de mundo da sociedade que o utiliza, sendo simultaneamente 0 reflexo, a sombra e o fragmento material dessa sociedade. A partir da análise dos empréstimos dessas duas línguas é possível observar importantes traços de suas culturas, e de suas perspectivas ideológicas.

\section{Referências}

ALVES, I. M. Empréstimos nas línguas de especialidade: al gumas considerações. Ciência da Informação, Brasília, v. 24, n. 3, 1995, pp. 319-321.

Aulete. F.C.; Valente, A. L. S. Dicionário Aulete Digital. Rio de Janeiro: Lexikon, 2008.

BAKTHIN, M. Estética da criação verbal. São Paulo: Martins Fonte, 1992.

BLOOMFIELD, L. Language. Nova York: H. Holt, 1933.

Bossong, G. 0 elemento português no japonês. In: Mendes, M. (org. ). A língua portuguesa em viagem. Actas do Colóquio Comemorativo do Cinquentenário do Leitorado de Português na Universiade de Zurique, 20 a 22 de junho de 1996. Frankfurt: Vertag, 2003.

FUKASAWA, L.M. Alguns aspectos da língua japonesa moderna- A língua enquanto elemento revelador da sua realidade. Estudos japoneses, São Paulo, n. 3, 1983.

GUILBERT, L. La créativité lexicale. Paris: Larousse, 1975.

Malmberg, B. A Língua e o Homem. Rio de J aneiro: Nórdica, 1976.

MICHAELIS. Dicionário prático de japonês-português. São Paulo: Aliança Cultural Brasil-J apão, 2012.

MILLER, A. 20 words of English origin that Japanese people often mistake for real thing. Lifestyle. 05 april 2013. 
SIQUEIRA, J.C. - O empréstimo e suas influências linguístico-culturais: o caso do japonês

NAITo, T. Sobre a estrutura da língua japonesa. Estudos japoneses, São Paulo, n. 1, 1979.

SAndmann, A.J. Morfologia lexical. São Paulo: Contexto, 1992.

TORII, R. Os processos de integração dos empréstimos linguísticos no Português. Tese (Doutorado em Linguística e Língua Portuguesa) Universidade Estadual Paulista, Faculdade de Ciências e Letras, Araraquara, 2007.

YAZAKI, G. Nihon no gairaigo. Tokyo: Iwanami Shoten, 1971. 